\title{
Selective and Reusable Iron(II)-Based Molecular Sensor for the Vapor-Phase Detection of Alcohols
}

\author{
Anil D. Naik, ${ }^{\dagger}$ Koen Robeyns, ${ }^{\dagger}$ Christophe F. Meunier, $^{\dagger}$ Alexandre F. Léonard, ${ }^{\ddagger}$ Aurelian Rotaru, ${ }^{\S}$ \\ Bernard Tinant, ${ }^{\dagger}$ Yaroslav Filinchuk, ${ }^{\dagger}$ Bao Lian $\mathrm{Su}^{\dagger}{ }^{\dagger}$ and Yann Garcia*, ${ }^{\dagger}$ \\ ${ }^{\dagger}$ Institute of Condensed Matter and Nanosciences, Molecules, Solids, Reactivity (IMCN/MOST), Université Catholique de Louvain, \\ Place Louis Pasteur 1, 1348 Louvain-la-Neuve, Belgium \\ ${ }^{\ddagger}$ Laboratoire de chimie des matériaux inorganiques, Département de Chimie, Université de Namur, 5000 Namur, Belgium \\ ${ }^{\S}$ Department of Electrical Engineering and Computer Science, “Stefan cel Mare” University, Suceava 720229, Romania
}

Supporting Information

ABSTRACT: A mononuclear iron(II) neutral complex (1) is screened for sensing abilities for a wide spectrum of chemicals and to evaluate the response function toward physical perturbation like temperature and mechanical stress. Interestingly, 1 precisely detects methanol among an alcohol series. The sensing process is visually detectable, fatigue-resistant, highly selective, and reusable. The sensing ability is attributed to molecular sieving and subsequent spin-state change of iron centers, after a crystal-to-crystal transformation.

$\mathrm{T}$ here is currently a huge appeal for "chemosensors" based on metal-organic frameworks (MOFs) for the sensitive and selective detection of gas- and vapor-phase analytes for a range of applications including chemical threat alerts, medical diagnostics, and environmental monitoring. ${ }^{1}$ Among a wide variety of materials, iron(II) spin-crossover molecular materials, which respond to a range of external stimuli (temperature, pressure, light irradiation, hard X-rays, humidity, etc.), have been developed, given their remarkable spectroscopic, visual/optical, magnetic, dielectric, or electrical readout signal, which makes these materials potentially considered for practical applications. ${ }^{2}$ Among them, iron(II) coordination polymers with several sorbing species are currently studied including alcohols, $\mathrm{CO}_{2}(\mathrm{~g}),{ }^{3} \mathrm{SO}_{2}(\mathrm{~g}),{ }^{4}$ etc.

In this context, we report herein the synthesis and characterization of a novel iron(II) mononuclear complex, and its ability to selectively differentiate and detect alcohols based on molecular sieving and spin-state change, thanks to an unprecedented mechanism involving a ligand replacement in the coordination sphere, provoking a color change, which are both not triggered by temperature, which differs from reported examples of MOFs. ${ }^{5}$

Using a simplified transamination reaction, ${ }^{6}$ we prepared 5(4H-1,2,4-triazolyl)- $2 \mathrm{H}$-tetrazole (trz-tet $\mathrm{H})$, wherein two azole molecules are connected without a spacer. With $\mathrm{Fe}\left(\mathrm{ClO}_{4}\right)_{2}$. $6 \mathrm{H}_{2} \mathrm{O}$ or $\mathrm{Fe}\left(\mathrm{BF}_{4}\right)_{2} \cdot 6 \mathrm{H}_{2} \mathrm{O}$, trz-tet $\mathrm{H}$ reacts in water at neutral $\mathrm{pH}$ to give a colorless, microcrystalline, air-stable complex ( $\mathbf{1}$; see the Supporting Information, SI). Rectangular colorless crystals $(\sim 2-3 \mathrm{~mm})$ of 1 crystallizing in the $P \overline{1}$ space group were grown from water (Table S1 in the SI). 1 is a mononuclear complex, $\left[\mathrm{Fe}(\text { trz-tet })_{2}\left(\mathrm{H}_{2} \mathrm{O}\right)_{4}\right] \cdot 2 \mathrm{H}_{2} \mathrm{O}$, with a $\mathrm{FeN} \mathrm{O}_{4}$ chromophore with monodentate triazole coordination (Figure 1).

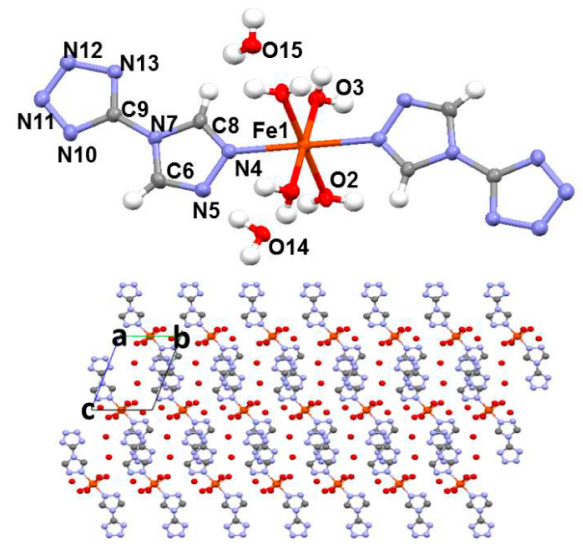

Figure 1. (Top) Molecular structure of 1. (Bottom) View along the $a$ axis of the crystal packing, showing the channels of water molecules. Hydrogen atoms were omitted for clarity.

The trz-tet molecule acts as an anionic ligand with deprotonation of the labile proton on the tetrazole moiety. Mononuclear units are arranged as parallel sheets in the crystal packing (Figure 1). These sheets are interpenetrated by similar neighboring planes wherein tetrazole of the mononuclear units is brought within 4.47-4.7 $\AA$ of the iron centers. This molecular arrangement creates interplanar spaces in the form of zigzag channels that are occupied by two lattice water molecules. These noncoordinated species are involved in a dense hydrogenbonding network (Table S3 in the SI), being connected to nitrogen atoms from a neighboring tetrazole moiety but also to coordinated water molecules (Figure S1 in the SI). The ${ }^{57} \mathrm{Fe}$ Mossbauer spectrum of $\mathbf{1}$ at $298 \mathrm{~K}$ shows a unique doublet with an isomer shift $\delta=1.17(2) \mathrm{mm} / \mathrm{s}$ and a quadrupole splitting $\Delta E_{\mathrm{Q}}$ $=3.18(3) \mathrm{mm} / \mathrm{s}$, which are typical for high-spin (HS) $\mathrm{Fe}^{\mathrm{II}}$ (Figure $2 \mathrm{a}) .^{7}$ The asymmetry in the doublet is due to texture. At $77 \mathrm{~K}$ (Table S2 in the SI), no spin switching is detected, which was expected for a $\mathrm{FeN}_{2} \mathrm{O}_{4}$ core including water molecules

Received: November 12, 2013

Published: January 13, 2014 
(a)
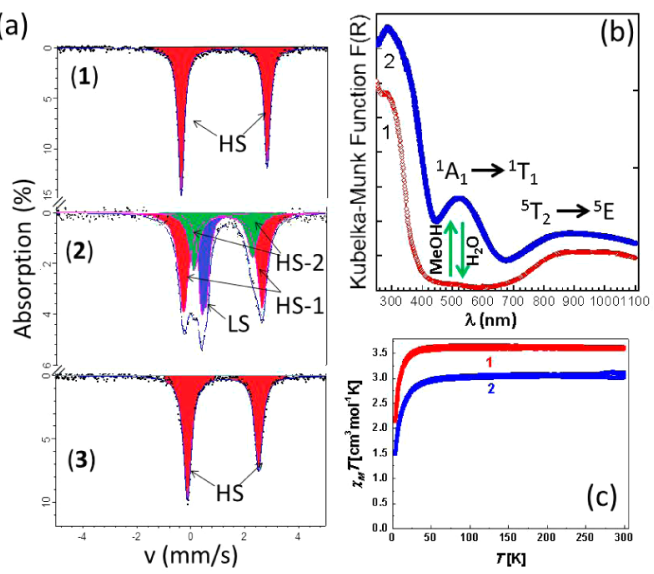

Figure 2. Spin-state tracking by (a) ${ }^{57} \mathrm{Fe}$ Mossbauer spectroscopy at 298 $\mathrm{K}$ (1) of $\mathbf{1},(2)$ of 2 after $\mathrm{MeOH}$ exchange, (3) of 2 treated with water, which shows reversibility (b). Diffuse-reflectance spectroscopy of $\mathbf{1}$ and 2 at $298 \mathrm{~K}$. (c). Thermal variation of $\chi_{\mathrm{M}} T$ for 1 and 2.

(Figure 1). The paramagnetic state is confirmed by SQUID measurements with a characteristic $\chi_{\mathrm{M}} T$ value for the HS state (Figure 2c). The HS state is also supported by the broad ${ }^{5} \mathrm{~T}_{2} \rightarrow$ ${ }^{5} \mathrm{E}$ band centered around $850 \mathrm{~nm}$ in the diffuse-reflectance spectrum (Figure 2b).

The thermogravimetric analysis (TGA) profile of 1 (Figure $\mathrm{S} 2 \mathrm{~b}$ in the SI) indicates that lattice water molecules are lost between 313 and $338 \mathrm{~K}$, whereas coordinated water molecules are lost between 378 and $403 \mathrm{~K}$. Lattice water molecules can also be removed by pumping-out crystals under vacuum $(3 \mathrm{mbar})$ for $3-4 \mathrm{~h}$ at $313 \mathrm{~K}$ or at room temperature for $8-10 \mathrm{~h}$. Crystals in the latter case retain their luster. When observed by scanning electron microscopy (SEM), periodic cracks on one broad side of a rectangular crystal are, however, detected (Figure 3c). Investigation of 1 by mercury intrusion porosimetry (MIP) shows a pore-size distribution of $80-100 \mu \mathrm{m}$ and indicates interparticle porosity (Figure $3 \mathrm{e}, \mathrm{f}$ ).

Such material should be inherently sensitive for host-guest interactions and constitutes a playground for molecular recognition. ${ }^{1}$ Our goal was to allow polar, hydrophilic, chemically
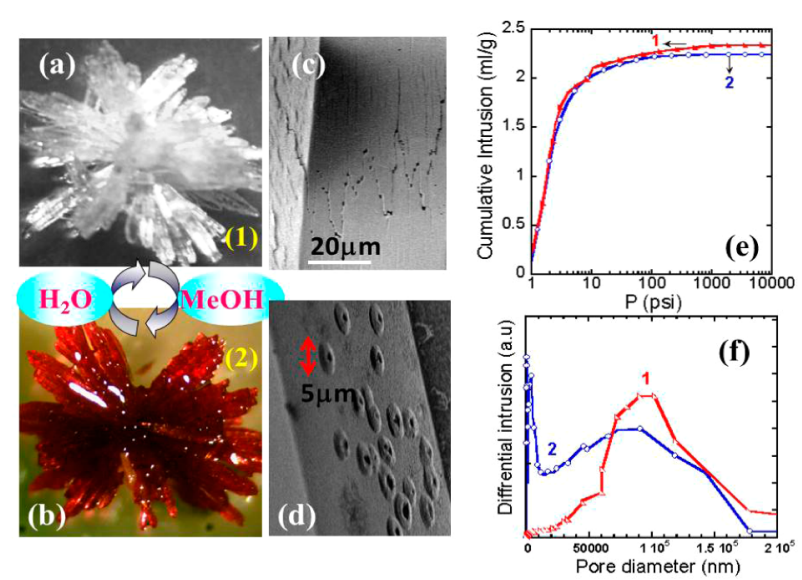

Figure 3. (a and b) Images depicting crystal-to-crystal vapochromic transformation upon $\mathrm{MeOH}$ sensing of $\mathbf{1}$ (colorless) and $\mathbf{2}$ (red). In part $\mathrm{b}$, the orientation of crystal bunch was modified because of the handling of such delicate crystals and the background color was changed during image recording and processing. (c) SEM image of 1. (d) SEM image of 2. (e) Intrusion curve. (f) Corresponding pore-size distribution. nonreactive, guest molecules that could traverse the empty channels of such crystals whose internal borders are lined up by switchable iron centers and a noncoordinated tetrazole moiety. A wide array of chemicals (alcohols, acids, $\mathrm{CHCl}_{3}, \mathrm{CH}_{2} \mathrm{Cl}_{2}$, $\mathrm{CH}_{3} \mathrm{CN}$, etc.) were thus exposed to $\mathbf{1}$, which was not desorbed prior to these experiments. Among them, 1 responds only to members of the alcohol and acid series. Among physical stimuli, 1 was nonresponsive to a change in temperature (298 to $77 \mathrm{~K}$ ) and light irradiation (UV-vis) but instantly changed its color to pale pink when subjected to mechanical stress (e.g., grinding) and returned to its original color when friction is halted. The present account was focused on the responsiveness of $\mathbf{1}$ toward alcohols.

When the native hydrate $\mathbf{1}$ is in contact with liquid methanol $[\mathrm{MeOH}(\mathrm{l})]$, at room temperature, it instantly turns to pale pink. The chromic response is intense when colorless crystals (2-3 $\mathrm{mm}$ length) are exposed to $\mathrm{MeOH}(\mathrm{g})$ (Figure 3a,b). This vapochromism is a crystal-to-crystal transformation. Crystals begin to turn pink within $5 \mathrm{~min}$, but take hours to transform into dark pink (2) as much as the atmosphere is saturated with $\mathrm{MeOH}$. This time duration is considerably reduced when crushed crystals or microcrystals are used. 1 selectively detects $\mathrm{CH}_{3} \mathrm{OH}$ over its heavier alcohol analogues by visual, spectral, optical, and magnetic feedback and reversibly turns back to colorless (3) when exposed to water vapor/washed with water for regeneration. This cycle has been repeated more than 100 times without deterioration, demonstrating the robustness of our molecular sensor. However, 1 loses crystal luster after the first cycle. The selectivity of detection decreases in the order $\mathrm{MeOH}$ $>\mathrm{EtOH}>\mathrm{PrOH}>\mathrm{BuOH}>\ldots$ with increasing alcohol size. These observations were noted under identical conditions as well as extension of the solvent vapor exposure period considering the vapor pressure of different members of the alcohol series. 1 also shows only a slight color change on the surface of the crystal when exposed to EtOH vapor, but eventually crystal luster is lost and detection is restricted. Higher analogues in the alcohol series were even exposed to 1 for several days; however, neither showed any color change or deterioration.

Among possible mechanisms of such analyte selectivity, size exclusion (molecular sieving) wherein alcohol molecules that are smaller than the apertures of the molecular channels of $\mathbf{1}$ can be allowed to traverse, whereas higher analogues cannot, is thought of. The response time of $\mathbf{1}$ depends on the rate of guest diffusion, physical state (solution/vapor), and proximity. The driving force for the striking color change at room temperature is due to a spinstate switching of $\mathrm{Fe}^{\mathrm{II}}$. Indeed, for $\mathbf{1}$ the $\mathrm{FeN}_{2} \mathrm{O}_{4}$ chromophore with coordinated water molecules (Figure 1) sets up a weak ligand-field strength (Figure 2). Thus, eventual substitution of coordinated water molecules in $\mathbf{1}$ by $\mathrm{MeOH}$ is not expected to shift the ligand-field strength into the low-spin (LS) region. However, a comparison of the diffuse-reflectance spectra (Figure $2 \mathrm{~b}$ ) of $\mathbf{1}$ and $\mathbf{2}$ clearly indicates a new band around $500 \mathrm{~nm}$ that is characteristic of the ${ }^{1} \mathrm{~A}_{1} \rightarrow{ }^{1} \mathrm{~T}_{1} \mathrm{~d}-\mathrm{d}$ transition of the LS state of $\mathrm{Fe}^{\mathrm{II}}$. SQUID magnetometry also supports this observation by the lower $\chi_{\mathrm{M}} T$ value for 2 . Structural information in addition to a quantitative analysis of spin-state change by Mössbauer spectroscopy was obtained. 2 reveals three signals (Figure 2a): a new quadrupole doublet in the center $\left[\delta=0.41(1) \mathrm{mm} / \mathrm{s} ; \Delta E_{\mathrm{Q}}=\right.$ $0.19(1) \mathrm{mm} / \mathrm{s}$ ] of $22 \%$, characteristic of a $\mathrm{LS}^{\mathrm{FeN}} \mathrm{N}_{6}$ core with azole ligands. Indeed, replacement of the oxygen atoms by nitrogen atoms, which are less electronegative, increases the electronic density of s electrons in the vicinity of the iron nucleus and thereby decreases the isomer shift. The two remaining contributions correspond to HS Fe ${ }^{\mathrm{II}}$ sites: ${ }^{8}$ HS-1 $[\delta=1.28(2)$ 
$\left.\mathrm{mm} / \mathrm{s} ; \Delta E_{\mathrm{Q}}=2.48(3) \mathrm{mm} / \mathrm{s} ; 39 \%\right]$ and HS-2 $[\delta=0.92(2) \mathrm{mm} /$ s; $\Delta E_{\mathrm{Q}}=2.51(3) \mathrm{mm} / \mathrm{s} ; 39 \%$ ]. Both correspond to $\mathrm{FeN}_{4} \mathrm{O}_{2}$ octahedra, ${ }^{8}$ which are more distorted than in $\mathbf{1}$. Not all iron sites are switched, which could be due to crystallographic modifications that restrict further $\mathrm{MeOH}$ diffusion. Reversibility was also confirmed by Mössbauer spectroscopy, which shows the complete disappearance of the LS signal in 3 after having experienced a water vapor atmosphere (Figure 2a).

The real-time observation of vapochromism and spatiotemporal aspects of the spin-state change with subsequent evolution of phase boundaries could be captured with a high-resolution optical microscope. A neat crystal of $\mathbf{1}$ was placed in a small Petri dish, which was immersed in a large Petri dish containing dry $\mathrm{MeOH}$. The whole assembly was covered and sealed. The microscope is focused on the tip of the crystal, and images were taken at successive intervals of time (Figure 4). The nucleation of

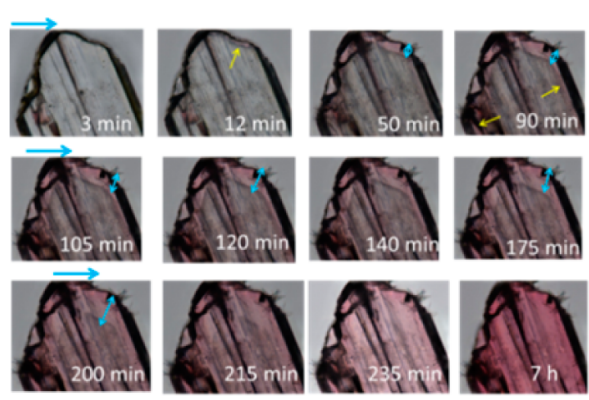

Figure 4. Real-time microscope imaging of a vapochromic spin-state change in $\mathbf{1}$ (2-3-mm-long crystal) at room temperature.

color change begins at a corner, covers the whole corner, and extends to the sides, and then the phase boundaries/color change fronts begin to move toward the center. ${ }^{9}$ The transformation time is drastically reduced when microcrystals are used. The direction of propagation of the color change is consistent with ligand exchange along the crystallographic $a$ axis, along which the channel of the coordinated water molecules is extended (Figure 1). In the presence of aqueous $\mathrm{MeOH}$, it is still possible to observe the chromism, but the diffusion time increases and the color change is not as intense. All attempts to characterize 2 by single-crystal diffraction failed because the crystals do not keep their integrity upon transformation, producing only powder diffraction rings. Unlike 1, intriguing-looking blisters, "microvolcanoes" ( $\sim 3 \mu \mathrm{m}$ size), on the crystal surface of 2 (Figure $3 \mathrm{~d}$ ) were detected in SEM images. MIP (Figure 3e,f) indicates 22-24 $\mu \mathrm{m}$ pores as a result of solvent exchange. IR and Raman spectra (Figure S3 in the SI) for 1 and $\mathbf{2}$ were not conclusive about a structural modification in 2. Powder X-ray diffraction (PXRD) supports, however, a molecular network reconstruction after solvent vapor exposure (Figure S2a in the SI). TGA provides further information (Figure S2b in the SI): 2 begins to lose weight starting from room temperature, unlike 1 . There is a small inflection around $388 \mathrm{~K}$ that coincides with weight loss corresponding to coordinated water molecules in 1 . However, the total weight loss in $\mathbf{2}(\sim 18 \%)$ is merely half that of $\mathbf{1}(\sim 37 \%)$. This would indicate that some of the water molecules are replaced by $\mathrm{MeOH}$ molecules. This substitution is expected to be part of an allosteric effect, ${ }^{10}$ wherein an uncoordinated tetrazole moiety of the neighboring mononuclear unit is displaced from its mean position to be coordinated to iron, thus leading to a LS $\mathrm{FeN}_{6}$ core, as detected by Mössbauer spectroscopy. Despite only a $\sim 1 / 5$ fraction of the molecules undergoing spin-state switching (as evaluated from Mössbauer data), the observed signal transduction is still significant. The main advantage of this chromogenic system is the striking signal transduction and operation at ambient temperature without the need for cryogenic facilities or temperature pretreatment. Undoubtedly, 1 could be investigated for future theoretical and practical investigations of spin-state propagation in the crystalline state. In particular, we could note that 1 not only selectively senses alcohols but also selectively detects hydrochloric acid among sulfuric, nitric, perchloric, and acetic acids in the solid state. Interestingly, $\mathbf{1}$ also responds to "mechanical friction" with reversible optical responsiveness. ${ }^{11}$ The fabrication of alcohol detection strips for mobile detector applications is planned.

\section{ASSOCIATED CONTENT}

\section{S Supporting Information}

X-ray crystallographic data in CIF format, experimental section with a reaction scheme, instrumentation, crystallographic data (Tables S1-S3), Mössbauer parameters (Table S4), a hydrogenbonding network (Figure S1), PXRD and TGA (Figure S2), FTIR and Raman (Figure S3), and visualization of crystal faces and Miller indices (Figure S4). This material is available free of charge via the Internet at http://pubs.acs.org.

\section{AUTHOR INFORMATION}

\section{Corresponding Author}

*E-mail: yann.garcia@uclouvain.be. Fax: (+)3210472330.

\section{Notes}

The authors declare no competing financial interest.

\section{ACKNOWLEDGMENTS}

This work was partly funded by the FRS-FNRS (Grants FRFC 2.4508.08 and 2.4537.12), RNASR, CNCS-UEFISCDI (Grant PN-II-RU-TE-2011-3-0307), Romanian Academy, WBI, and the COST action MP1202.

\section{REFERENCES}

(1) Kreno, L. E.; Leong, K.; Farha, O. K.; Allendorf, M.; Van Duyne, R. P.; Hupp, J. T. Chem. Rev. 2012, 112, 1105.

(2) Gütlich, P.; Gaspar, A. B.; Garcia, Y. Beilstein J. Org. Chem. 2013, 9, 342.

(3) Coronado, E.; Gimenez-Marques, M.; Minguez Espallargas, G.; Rey, F.; Vitorica-Yrezabal, I. J. J. Am. Chem. Soc. 2013, 135, 15986.

(4) Arcís-Castillo, Z.; Muñoz-Lara, F. J.; Muñoz, M. C.; Aravena, D.; Gaspar, A. B.; Sánchez-Royo, J. F.; Ruiz, E.; Ohba, M.; Matsuda, R.; Kitagawa, S.; Real, J. A. Inorg. Chem. 2013, 52, 12777.

(5) (a) Hadler, G. J.; Kepert, C. J.; Moubaraki, B.; Murray, K. S.; Cashion, J. D. Science 2002, 298, 1762. (b) Neville, S.; Halder, G.; Chapman, K.; Duriska, M.; Southon, P.; Cashion, J.; Létard, J. F.; Moubaraki, B.; Murray, K.; Kepert, C. J. Am. Chem. Soc. 2008, 130, 2869. (c) Ohba, M.; Yoneda, K.; Agustí, G.; Muñoz, M. C.; Gaspar, A. B.; Real, J. A.; Yamasaki, M.; Ando, H.; Nakao, Y.; Sakaki, S.; Kitagawa, S. Angew. Chem., Int. Ed. 2009, 48, 4767.

(6) Naik, A. D.; Marchand-Brynaert, J.; Garcia, Y. Synthesis 2008, 1, 149.

(7) Gütlich, P.; Garcia, Y. In Mössbauer Spectroscopy; Yoshida, Y., Langouche, G., Eds.; Springer: Berlin, 2013; Chapter 2, pp 23-89.

(8) Robert, F.; Naik, A. D.; Tinant, B.; Robiette, R.; Garcia, Y. Chem.Eur. J. 2009, 15, 4327.

(9) Varret, F.; Slimani, A.; Boukheddaden, K.; Chong, C.; Mishra, H.; Collet, E.; Haasnoot, J. G.; Pillet, S. New J. Chem. 2011, 35, 2333.

(10) Niel, V.; Thompson, A. L.; Muñoz, M. C.; Galet, A.; Goeta, A. E.; Real, J. A. Angew. Chem., Int. Ed. 2003, 42, 3760.

(11) Ito, H.; Muromoto, M.; Kurenuma, S.; Ishizaka, S.; Kitamura, N.; Sato, H.; Seki, T. Nat. Commun. 2013, 4, 2009. 